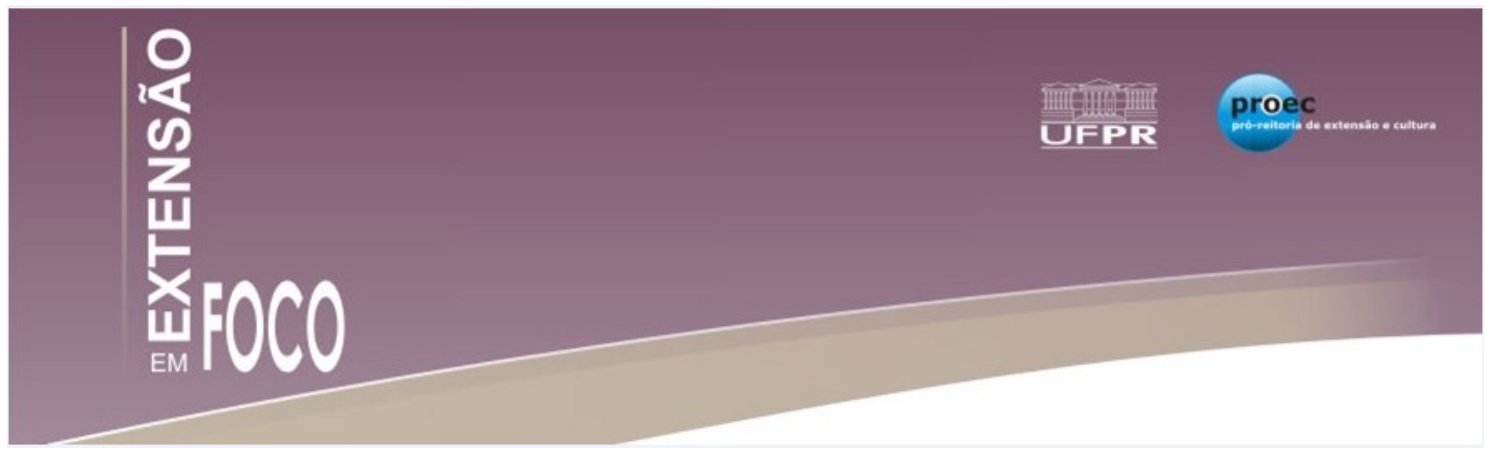

\title{
ATUAÇÃO DOS CINCO ANOS DO PROJETO DE EXTENSÃO: USO EFICIENTE DE ENERGIA NA UFERSA ${ }^{1}$
}

Humberto Henrique ${ }^{2}$, Amanda Suianny², Fernando Jackson², Luann Georgy ${ }^{2}$

${ }^{1}$ Aceito para Publicação no $2^{\circ}$ Semestre de 2016

${ }^{2}$ Universidade $\quad$ Federal Rural do Semi- Árido;

humbertojrhumberto@hotmail.com; amanda_suianny@hotmail.com; jjackson123@hotmail.com; luanngeorgy@hotmail.com.

\section{RESUMO}

O presente artigo tem por objetivo apresentar o andamento do Projeto de Extensão "Uso Eficiente de Energia na UFERSA" em seus cinco anos de atuação. Inicialmente, o Projeto é apresentado brevemente. Em seguida, são destacadas as principais atividades realizadas, no período de 2011 até 2015, enfatizando a consolidação das ações para promoção de eficiência energética na comunidade interna e externa da Instituição; e a influência do consumo e da demanda de energia elétrica da Universidade, que se encontra em fase de expansão. Por fim, destacam-se os pontos relevantes da análise proposta, tendo como foco a gestão energética dentro da Universidade.

Palavras- chave: Extensão; Educação; Meio Ambiente; Tecnologia 


\section{INTRODUÇÃO}

Atualmente, comenta-se com maior frequência, a respeito da Eficiência Energética, essa atenção repentina, deve-se ao fato de que o país passa por uma grande crise energética, e econômica. Basicamente a eficiência energética, consiste em desempenhar de forma satisfatória, um determinado serviço, gastando o mínimo de energia possível (CELPE, 2013). Dessa forma, percebe-se que tornar a eficiência energética uma realidade no dia a dia das pessoas é de suma importância, pois acarreta benefícios significativos para toda a população.

Diante disso, em abril de 2011, foi criado no âmbito da Universidade Federal Rural do Semiárido (UFERSA), o Projeto de Extensão "Uso Eficiente de Energia na UFERSA", desenvolvido por professores e alunos do curso de Engenharia de Energia da Universidade, campus Mossoró/RN (UFERSA, 2011). Este Projeto tem caráter permanente, e ocorre anualmente há anos.

Partindo da premissa, de que as universidades têm uma grande influência na formação dos discentes, esse pode ser o passo inicial para desenvolver meios que ampliem o interesse de cada um, no que diz respeito à eficiência energética como um todo.

A necessidade de avaliar as condições gerais da infraestrutura da Universidade em relação ao uso da energia elétrica foi consideradao foco principal para a criação do projeto em questão(SILVA et. al., 2012), que visa contribuir para o gerenciamento do uso de energia elétrica $e$ consequentemente a economia desta, além de promover a disseminação dos conceitos do uso racional e eficiente de energia na comunidade universitária e na sociedade.

Desde a sua criação, ou seja, desde 2011 até os dias atuais, foram realizadas diversas atividades, com o objetivo de traçar melhor o perfil de consumo e demanda de energia elétrica, e consequentemente, melhoraro gerenciamentodos gastos e do uso racional de energia da Universidade. Dentro deste contexto, o presente trabalho tem como objetivo expor sucintamente as principais ações desenvolvidasno Projeto ao longo dos seus cinco anos de 
atuação, além de mostrar que tais resultados podem influenciar diretamente nas próximas etapas a serem realizadas e implementadas.

\section{OS CINCO ANOS DO PROJETO "USO EFICIENTE DE ENERGIA NA UFERSA"}

Em cinco anos de atuação do projeto, diversas atividades foram desenvolvidas. Tais ações e atividades propostas foram realizadas como mostram os itens 2.1, 2.2, 2.3, 2.4 e 2.5.

\subsection{Ano I}

O projeto de extensão "uso eficiente de energia na UFERSA" foi criado em 2011 com a ideia inicial de conscientizar a comunidade acadêmica sobre a importância da conservação de energia e suas vantagens. O ponto de partida foi à identificação dos principais meios de desperdício da universidade além da aplicação de questionários, que tinham como objetivo a quantificação do grau de conhecimento e consciência dos alunos, professores e funcionários.

A primeira atividade do projeto no primeiro ano de sua criação, não atingiu os resultados desejados, devido à relutância de alguns, mas serviu de incentivo à elaboração dos primeiros planos e ações. As entrevistas abordavam perguntas simplificadas sobre o comportamento individual e em relação ao bem maior, ou seja, qual era o tempo de permanência das pessoas em suas salas com os equipamentos ligados; como as mesmas quantificavam seus consumos ao longo do tempo; se elas se incomodavam com o desperdício de outrem ou se tomavam atitudes referentes ao desperdício geral, como por exemplo, desligar luminárias nassalas desocupadas, entre outras.

Com base nos resultados obtidos, foi elaborado e divulgado um material específico visando promover a conscientização destes usuários. Nesta etapa, foram elaboradas cartilhas, panfletos e as etiquetas de conscientização do consumo, que faziam a relação entre a energia desperdiçada na Universidade e a verba que poderia ser investida em melhorias, como livros para a biblioteca e equipamentos para os laboratórios, como mostra a Figura 1. 
Figura 1 - Etiqueta informativa utilizada pelo Projeto de Extensão - Uso Eficiente de Energia na UFERSA

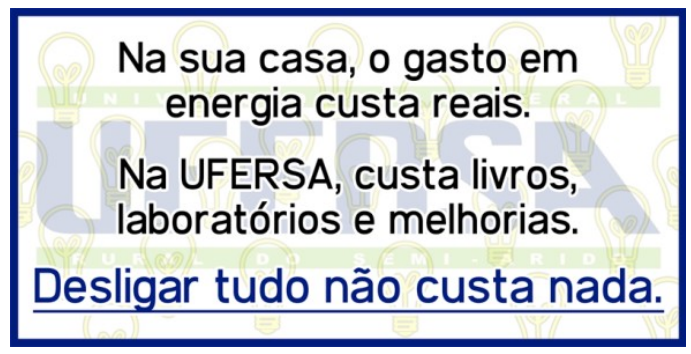

Fonte: SILVA et. al., 2012.

A etiquetagem foi organizada e executada pelos próprios integrantes do projeto. Foram inseridas na maioria dos prédios de livre acesso, sempre abaixo ou acima das tomadas com intuito de comunicar aos usuários sobre o desperdício de energia elétrica.

A segunda atividade realiza dano ano Iteve início com os estudos sobre o comportamento do consumo da Universidade (UFERSA, 2011). Tal estudo permitiu a observação do aumento do consumo ao longo do tempo, no caso, uma análise de 2005 e 2011, bem como alterações na demanda que vinha sendo contratada, levando em consideração o período considerado.

Foram relatados alguns problemas desta etapa, sendo dois os principais deles, a saber, as dificuldades de obtenção dos dados tarifários completos, e o fato da medição da universidade ser centralizada, ou seja, em única fatura de energia. Sendo assim, não foi possível identificar de forma pontual os locais (prédios)responsáveis pelo maior consumo ou desperdício de energia elétrica.

As dificuldades da segunda atividade foram o marco de início da atividade seguinte, pois essa etapa passou a ser menos centralizada e buscou a consciência geral da comunidade acadêmica, através de palestras educativas, tratando sobre o tema "eficiência energética" em escolas públicas da região durante a Semana Nacional de Ciência e Tecnologia (SNCT) da FAPERN - Fundação de Apoio a Pesquisa no Rio Grande do Norte, ocorrida em 2011. 
$\mathrm{Na}$ terceira etapa do referido ano, teve o início a elaboração de diagnósticos energéticos, visando detectar problemas e sugerir correções através de medidas mais inteligentes e eficientes (UFERSA, 2011). Logo, a ideia era diminuir o consumo, além de realizarum estudo sobre possíveis mudanças tarifárias com o intuito de amenizar o desperdício de energia elétrica e financeiro.

Ao final do presente ano, foi elaborado um relatório conclusivo a respeito do consumo e dos desperdícios de energia elétrica, bem como alterações na futura demanda a ser contratada no ano subsequente, que foi apresentado ao setor administrativo da Universidade.

\subsection{Ano II}

Em abril de 2012 deu-se início ao ano II do projeto, que sofreu algumas adaptações e alterações, contando também com a inclusão de novos alunos participantes e professores colaboradores. Para a realização das atividades propostas no ano em questão, o Projeto foi dividido em cinco etapas, com três grupos de trabalho, atuantes em três diferentes áreas, saber, análise da qualidade de energia, análise das faturas de energia e análise da memória de massa da Universidade (UFERSA, 2012).

Neste ano, o projeto acompanhou a instalação da climatização de algumas salas de aula da Universidade, e principalmente como tais equipamentos afetariam a demanda da Universidade. Os trabalhos de análise foram feitos através de relatórios. Também foram elaboradas novas etiquetas visando orientar aos usuários das salas de aula, sobre o uso racional dos aparelhos de ar-condicionado.

Ainda neste ano, continuaram-se as palestras educativas nas escolas, além da produção de artigos e relatórios de consumo e demanda de energia da Universidade. Os participantes elaboraram artigos utilizando dados compilados do ano I, e assim, foi publicado e apresentado o primeiro artigo no VIII Congresso Brasileiro de Planejamento Energético - CBPE, em agosto de 2012, Curitiba/PR (SILVA et. al., 2012). Além disso, foram publicados dois artigos científicos na Revista EXTENDERE, volumes 1 e 2, em 2013, tratando sobre a 
análise de demanda e consumo de energia elétrica; e sobre a análise detalhada da estrutura elétrica da Universidade.

Assim como no ano I, no ano II, houve também a participação dos membros do Projeto na Semana Nacional de Ciência e tecnologia, por meio da FAPERN, onde os alunos deslocaram-se até as escolas da comunidade e promoveram palestras sobre temas relacionados à eficiência energética e reciclagem. Entre os assuntos abordados estão: "fontes alternativas de energia: aproveitando a energia do sol e dos ventos" e "uma nova visão sobre o lixo", sempre como foco a eficiência energética e uso racional de energia elétrica.

Ao fim do período foram elaborados relatórios com análises de todos os resultados obtidos, incluindo sugestões e propostas com intuito de complementar os conhecimentos na área de atuação do Projeto, bem como a sinalização quanto à necessidade de desenvolvimento de pesquisas específicas neste tema dentro da Universidade.

\subsection{Ano III}

O Ano III, iniciado em abril de 2013, começou com novos integrantes e teve como objetivo dar continuidade as principais atividades do ano anterior. Além disso, foram realizadas análises dos dados obtidos nos anos I e II, possibilitando quantificar a evolução do projeto ao longo do tempo e o quanto a inserção dos aparelhos condicionadores de ar nas salas de aula, em 2012, impactou o consumo de energia elétrica da Universidade (UFERSA, 2013).

Como já esperado, com o crescimento da universidade houve crescimento do consumo, e novas análises de demanda e consumo se fizeram necessárias. Além disso, foi necessária a ampliação do alcance do programa de etiquetagem já iniciado no ano I do projeto, e palestras educativas. No caso das etiquetas, as mesmas foram afixadas nos prédios novos da instituição, além da reposição das mesmas nos prédios antigos, caso fosse necessário. Já as palestras educativas, começaram a serem realizadas mensalmente, tendo sempre como foco as escolas municipais da região.

Em relação a publicações, e para fechar o ano III, foi publicado e apresentado um artigo no XLI COBENGE (FILGUEIRA, et al., 2013), que fez 
considerações sobre o projeto de extensão e a interdisciplinaridade na formação do engenheiro de energia.

\subsection{Ano IV}

O ano IV, iniciado em abril de 2014, dando continuidade às atividades realizadas nos anos anteriores, ou seja, nos anos I, II e III, contou com a participação desete discentes. Inicialmente, dando continuidade à etiquetagem, e com um perceptível aumento no número de prédios na UFERSA, que está em fase de expansão, uma nova etapa de etiquetagem foi necessária. Assim, foi elaborado um relatório abordando o controle da etiquetagem, ou seja, o alcance de novos prédios que necessitaram de etiquetas e reposição nos prédios mais antigos. Como resultado, foi inserido um total de 252 etiquetas.

Ainda no ano IV, foi elaborado o relatório sobre a tarifação da Universidade, desde sua criação, no caso desde 2005, até o ano de 2013, ano anterior ao projeto, possibilitando analisar o período inteiro proposto. Com isso, foi possível acompanhar o crescimento da demanda e consumo da instituição ao longo do tempo, além do impacto da greve, ocorrida em 2012, e da instalação dos condicionadores de ar nas salas de aula, também ocorrida em 2012, e já relatada anteriormente, sobre as tarifas da Universidade. De forma geral, o relatório foi organizado por meios de gráficos e tabelas, que melhor expressaram as informações. Individualmente os relatórios anuais são importantes para que se possa estimar a situação da faculdade em função das demandas (medidasxcontratadas) e consumo (pontaxfora da ponta).

Ainda neste ano, as palestras nas escolas continuaram, e essa etapa aconteceu como demonstrada na Tabela 1. 
Tabela 1- Resumo da organização das visitas às escolas ao longo de 2014.

\begin{tabular}{|l|l|l|}
\hline Escola & Mês & Detalhes \\
\hline Municipal Celina Guimarães & Maio & $\begin{array}{l}\text { Palestra educativa, em que o público } \\
\text { alvo foi os pais dos alunos da escola. } \\
\text { No conteúdo programático da } \\
\text { apresentação, foram abordados os } \\
\text { aspectos gerais sobre o uso racional } \\
\text { de energia elétrica no dia a dia. }\end{array}$ \\
\hline Escola Estadual Inalda \\
Cabral & Agosto & $\begin{array}{l}\text { Foram discutidos temas condizentes } \\
\text { com o cotidiano dos ouvintes, como o } \\
\text { uso correto dos aparelhos elétricos, } \\
\text { redução dodesperdícioe redução do } \\
\text { consumo, utilizando de medidas de } \\
\text { conservação de energia. }\end{array}$ \\
\hline Escola Estadual Monsenhor & Outubro \\
Raimundo Gurgel & $\begin{array}{l}\text { Abordagem da palestra voltada para a } \\
\text { importância da economia de energia } \\
\text { ecálculos básicos de consumo e } \\
\text { tarifas, com o intuito de preparar os } \\
\text { alunos para uma competição entre } \\
\text { trabalhos científicos. O grupo } \\
\text { apresentou uma proposta de economia } \\
\text { na iluminação da escola. }\end{array}$ \\
\hline
\end{tabular}

Fonte: Autoria Própria.

Neste ano IV do Projeto, mudou-se a abordagem de apresentações na SNCT da FAPERN, pois nas edições anteriores os alunos da UFERSA dirigiram-se até as escolas, onde eram realizadas palestras e atividades do evento. Na edição 2014 as atividades consistiram em trazer a comunidade escolar para conhecer e vivenciar as instalações da Universidade. Nesta ação foram contemplados alunos do $8^{\circ}$ e $9^{\circ}$ ano escolar. As atividades desenvolvidas foram: a apresentação dos laboratórios da universidade aos alunos; palestras sobre energias renováveis e a importância da conservação de energia; e palestras sobre a importância do engenheiro de energia/eletricista.

No mês de novembro de 2014 , os integrantes do projeto de extensão promoveram uma palestra educativa com o tema "Uso Racional de Energia", ministrada pelo gestor de eficiência energética da concessionária local de fornecimento de energia elétrica, COSERN. O público em questão foram os estudantes, professores e técnicos administrativos da Universidade. A palestra teve por objetivo informar a comunidade acadêmica sobre a importância da 
conservação de energia; eliminação dos desperdícios; e sobre os programas visando eficiência energética implementados pela COSERN.

Dando continuidade à realização de apresentações, em janeiro de 2015, foi realizado um minicurso específico, com o tema "Matlab básico", que constitui de um software interativo voltado para o cálculo numérico. O minicurso abrangeu 24 estudantes do curso de Engenharia de Energia, incluindo os membros do projeto de extensão. O softwareMatlab é bastante utilizado no meio acadêmico, principalmente em cursos de engenharia, sendo desta forma uma ferramenta útil quando relacionado à compilação de dados para base estatística, como é o caso de alguns estudos relacionados à eficiência energética.

Como algumas atividades elaboradas envolvem participação de discentes da UFERSA, como apresentação de palestras e minicursos, consequentemente outra atribuição dos integrantes do projeto é a preparação dos certificados de participação, que está incluído na organização geral das apresentações.

\subsection{AnoV}

No ano de 2015, um ano de crise energética e econômica, a economia de energia se vê necessária ainda mais. Com o grande declínio da intensidade das chuvas no país, a quantidade de energia gerada pelas hidrelétricas foi reduzida demasiadamente, obrigando o acionamento, com maior intensidade, das usinas térmicas, energia suficiente, mas de valor mais elevado, gerando maiores gastos.

Diante disso se torna ainda mais evidente a importância do uso racional de energia por parte dos consumidores, a redução de consumo por parte de cada cidadão gera vantagens significativas para a economia. 
No Ano $\mathrm{V}$ o projeto de extensão teve seu número de participantes reduzido para quatro alunos do curso Engenharia de Energia, visando com isso uma maior versatilidade de ocorrer o trabalho em grupo. Com menos componentes desempenhando o trabalho proposto pelo projeto de pesquisa, vêm-se obtendo bons resultados, continuando, como nos anosanteriores, arealização de palestras educacionais que visam informação e a conscientização da comunidade sobre um melhor uso da energia elétrica através demudanças simples de hábito.

Tendo em vista a diminuição de gastos de energia na universidade, uma das medidas tomadas pelos responsáveis do setor elétrico da UFERSA, foi a adoção de um novo contrato de demanda de energia. O reajuste de demanda no ano de 2015 se deu, principalmente, pelos desperdícios de aproximadamente 100 mil reais, gastos com multas e reativos excedentes. Com os ajustes feitos, esperava-se grandes resultados de economia no ano de 2015, no entanto o consumo de energia diminuiu devido a universidade está enfrentando um período de greve, e a redução referente ao novo contrato de demanda, ainda não foi sentida, uma vez que estão sendo pagos altos valores, equivalentes a demanda contratada atual, sem realmente estarem sendo consumidos. No Ano $\mathrm{V}$ foram elaborados relatórios, baseados em análises feitas nas faturas de energia dos anos de 2014 e 2015, visando observar onde estão os maiores desperdícios, para que possam ser corrigidos.

Preocupados com a situação atual do país, tentando minimizar os altos desperdícios gerados principalmente pelas indústrias, e integrar os alunos no mercado de trabalho, a Fundação Guimarães Duque coordenada pelo professor André Pedro, vinculou uma parceria com o SEBRAE para permitir que discentes e docentes do curso de engenharia de energia da UFERSA, fizessem parte do programa "Ligado na Economia", que consiste basicamente, em realizar diagnósticos energéticos nas empresas cadastradas no SEBRAE, e indicar possíveis soluções para os problemas encontrados. Um dos tutores participantes do programa, a professora Fabiana Varella, também coordenadora do projeto de extensão, deu prioridade aos alunos que fazem parte do seu projeto, dado que os temas estão diretamente ligados. 
A meta de elaboração mensal de palestras sobre eficiência energética dentro de escolas da cidade de Mossoró foi mantida nesse ano $\mathrm{V}$, tendo início no mês de maio. No entanto, vale ressaltar que nos meses de junho, julho e agosto, a aplicação das palestras foi interrompida devido a greve das universidades federais no qual a UFERSA se encontra. Um resumo sobre cada palestra feita até então pode ser encontrado na Tabela 2.Na Figura 2 é exibida parte da apresentação dessas palestras e em seguida, na Figura 3, é mostrado alguns dos alunos participantes.

Tabela 2- Resumo da organização das visitas às escolas ao longo de 2015.

\begin{tabular}{|c|c|c|}
\hline Escola & Mês & Detalhes \\
\hline Colégio Estúdio Visão & Maio & $\begin{array}{l}\text { No conteúdo programático da } \\
\text { apresentação, foram abordados os } \\
\text { aspectos gerais sobre o uso racional } \\
\text { de energia elétrica no dia a dia, assim } \\
\text { como conceitos básicos relacionados à } \\
\text { energia elétrica, cálculos básicos de } \\
\text { consumo e tarifas, como utilizar } \\
\text { corretamente aparelhos elétricos, como } \\
\text { reduzir o desperdício e o consumo etc. }\end{array}$ \\
\hline $\begin{array}{l}\text { Escola Estadual Prof. } \\
\text { Hermógenes Nogueira }\end{array}$ & Setembro & $\begin{array}{l}\text { Palestra educativa realizada para } \\
\text { alunos do terceiro ano do ensino } \\
\text { médio. No conteúdo programático da } \\
\text { apresentação, foram abordados os } \\
\text { aspectos gerais sobre o uso racional } \\
\text { de energia elétrica no dia a dia, assim } \\
\text { como conceitos básicos relacionados à } \\
\text { energia elétrica, cálculos básicos de } \\
\text { consumo e tarifas, como utilizar } \\
\text { corretamente aparelhos elétricos, como } \\
\text { reduzir o desperdício e o consumo etc. }\end{array}$ \\
\hline CAIC ABOLIÇÃO IV & Setembro & $\begin{array}{l}\text { Palestra educativa, em que o público } \\
\text { alvo foram alunos de } 20 \text { anos. No } \\
\text { conteúdo programático da } \\
\text { apresentação, foram abordados os } \\
\text { aspectos gerais sobre o uso racional } \\
\text { de energia elétrica no dia a dia, assim } \\
\text { como conceitos básicos relacionados à } \\
\text { energia elétrica, cálculos básicos de } \\
\text { consumo e tarifas, como utilizar } \\
\text { corretamente aparelhos elétricos, como } \\
\text { reduzir o desperdício e o consumo etc. }\end{array}$ \\
\hline
\end{tabular}

Fonte: Autoria Própria. 
Figura 2 - Parte da apresentação das palestras educativas

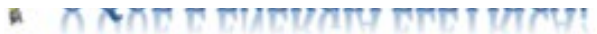

Uma das formas de Iergia mais utilizadas no undo, a Energia Elétrica presenta a capacidade ie uma corrente elétrica m de realizar trabalho, seando-se na produção Idiferenças de potencial étrico entre dois pontos ! um condutor.

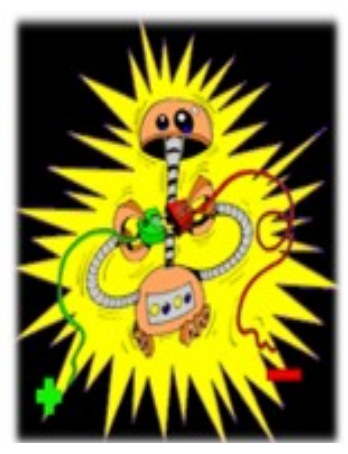

药

FORMA EFICIENTE?

- Ao usar a energia elétrica de maneira correta, é possivel economizar na conta de luz $\mathrm{e}$ ainda ajudar o país a preservar suas reservas ecológicas.

- Quanto maior o desperdício de energia, maior o preço que vorê $a$ a mein ambiente

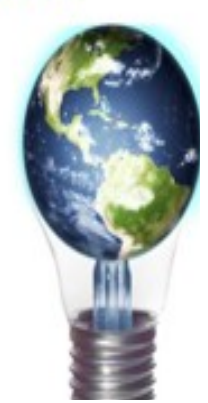

Fonte: Autoria própria.

Figura 3 - Alunos durante a palestra.

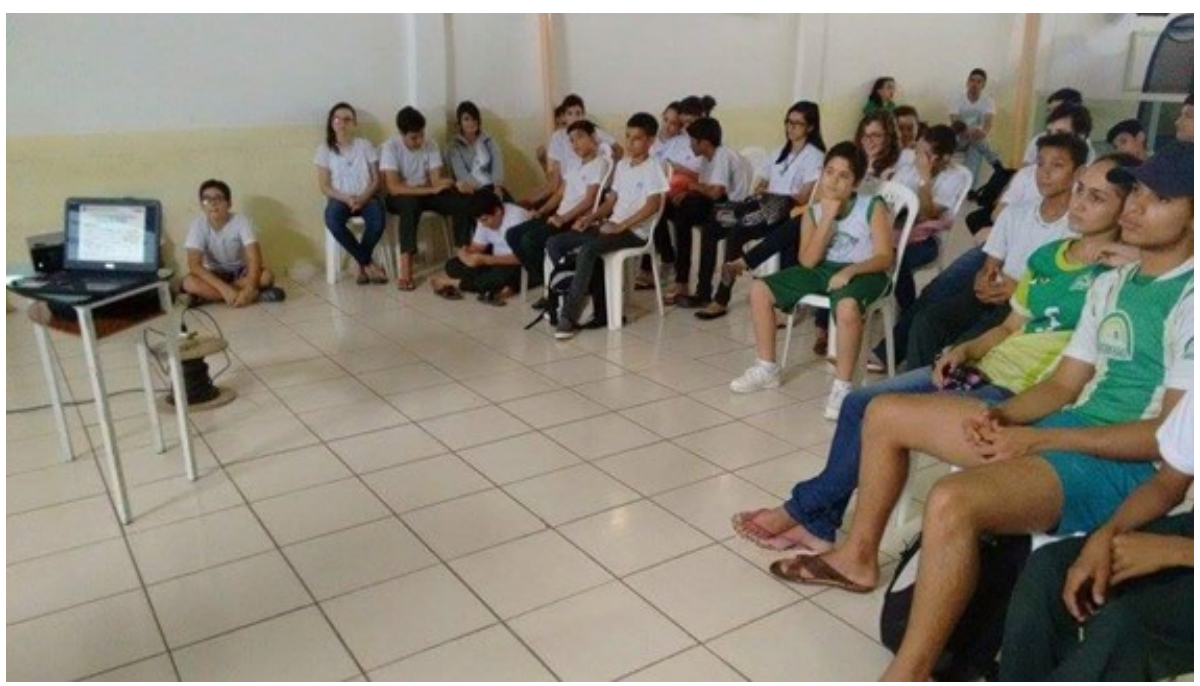

Fonte: Autoria Própria 


\section{ANÁLISE DOS CINCO ANOS DE ATUAÇÃO E PRÓXIMAS ETAPAS DO PROJETO}

Durante a execução dos cinco anos do projeto, existiram algumas dificuldades para obter um melhor resultado em algumas atividades. Tais problemas podem ser abordados separadamente como projetos futuros de melhoria.

Um dos problemas mais críticos se refere à medição da energia elétrica na UFERSA, que era obtida de forma centralizada. Como tal unidade consumidora é relativamente grande e possui várias divisões de prédios, setores e processos, a identificação dos pontos de maior consumo foi impossibilitada, dificultando assim a correção e identificação pontual dos desperdícios no uso da energia elétrica.

A partir do mês de outubro de 2014, com a individualização da medição entre os campos (Leste e Oeste) da universidade, a análise do consumo de energia elétrica tornou-se mais adequada. No entanto, como ainda não ocorre a medição individualizada por setor/departamento, essa análise ainda não é a idealpara identificar os maiores pontos consumidores, e para produzir ações de eficiência energética que teriam foco em tais pontos, realizando um estudo para relacionar tal consumo excessivo com suas possíveis causas e realizar o tratamento do consumo.

Com o objetivo de tornar realidade o descrito anteriormente a respeito da medição individual, torna-se necessário um estudo de viabilidade técnica e econômica para implantação de tais medidores, relacionando também todos os pontos de melhoria, e caso preciso, apresentar os resultados para o órgão da universidade responsável pela execução do Projeto. Hoje, já existe uma solicitação formal para tal implantação, porém não obteve sucesso.

Outra dificuldade também encontrada, nesses cinco anos de projeto, é referente às palestras educacionais realizadas nas escolas. Muitas das escolas procuradas pelos integrantes nem sempre estavam disponíveis, restando aos membros do projeto saírem em busca de outra instituição.

\section{CONCLUSÃO}


Ao longo dos anos, foi observada sempre a participação do projeto de extensão junto à universidadeea comunidade. A participação na universidade ocorreu de várias formas: palestras, minicursos, diagnósticos energéticos, analise de memória de massa, cartilhas, folders etiquetas e etc.. $\mathrm{Na}$ comunidade foram elaboradas palestras educativas, cartilhas, folders, dinâmicas de grupo e visita a universidade. Essas ações foram focadas em um ponto principal, conscientizar as pessoas sobre o uso racional de energia.

Evidenciou-se que o problema, em relação à economia de energia, é a conscientização, o projeto abordou propostas de soluções para o desperdício, além de acompanhar o crescimento do consumo ao longo dos anos, principalmente os consumos na ponta, além disso, as palestras educativas tiveram como objetivo despertar as crianças sobre a importância da economia de energia na escola em casa no trabalho e etc.

O projeto teve muitos pontos positivos, na universidadeaderiu-se a medição descentralizada por campi, melhor engajamento da gestão na utilização e aquisição de equipamentos, por exemplo, os condicionadores de ar mais eficientes e políticas de conservação de energia. Na comunidade, a visita dos alunos proporcionou uma ligação escola universidade, que permite bons momentos para os estudantes, principalmente da rede pública que puderam visitar a universidade.

Para os estudantes de engenharia de energia houve a possibilidade de trabalhar com análises energéticas além do contato com os alunos das escolas, aperfeiçoando assim suas habilidades de comunicação, pois a interdisciplinaridade das atividades realizadas auxilia significativamente na consolidação dos conhecimentos adquiridos em sala de aula e consequentemente complementam seu crescimento pessoal como indivíduos, por fim, a extensão permitiu a divulgação da própria universidade, como também, do curso de engenharia de energia, fazendo dessa, uma parceria que trouxe bons resultados a todos.

\section{REFERÊNCIAS BIBLIOGRÁFICAS}


FILGUEIRA, A.A.L., CRISÓSTOMO, D.C.C., VARELLA, F.K.O.M., CRUZ, F.M.,SANTIAGO, G.L.S., ANDRADE, H.D.A importância da interdisciplinaridade no projeto de extensão "uso eficiente de energia na ufersa" na formação do engenheiro de energia. XLI Congresso Brasileiro de Educação em Engenharia. COBENGE. Gramado/PR, 2013.

SILVA, Y. F. F. C., GUERRA, M. I. S., MAIA, C. O., VIEIRA, R. G., NETO, J. A. B., COSTA, V. P., DANTAS, F. E. F., VARELLA, F. K. O. M. Projeto de Extensão Uso Eficiente de Energia da Universidade Federal Rural do Semi-Árido. Congresso Brasileiro de Planejamento Energético. CBPE. Curitiba/PR, 2012.

UFERSA. Universidade Federal Rural do Semi-Árido. Relatório de Atividades do Projeto Extensão ANO I. Mossoró/RN, 2011.

. Universidade Federal Rural do Semi-Árido. Relatório de Atividades do Projeto Extensão ANO II. Mossoró/RN, 2012.

. Universidade Federal Rural do Semi-Árido. Relatório de Atividades do Projeto Extensão ANO II. Mossoró/RN, 2013. 